\title{
Thinking and Scientific Language in the Primary Classes
}

\author{
Saleh Y. Abo-Romi \\ 1502, Tamra, Israel \\ Email: Salihaboromi@gmail.com
}

How to cite this paper: Abo-Romi, S. Y. (2020). Thinking and Scientific Language in the Primary Classes. Creative Education, 11, 820-833.

https://doi.org/10.4236/ce.2020.115059

Received: March 26, 2020

Accepted: May 24, 2020

Published: May 27, 2020

Copyright (C 2020 by author(s) and Scientific Research Publishing Inc. This work is licensed under the Creative Commons Attribution International License (CC BY 4.0).

http://creativecommons.org/licenses/by/4.0/

\begin{abstract}
According to psychological and cognitive development theories, the preferences of pupils in elementary school toward inductive versus deductive and general types of reasoning when asked to prove or review mathematical claims, changes along the school years. This study examines this hypothesis through a survey in which 267 pupils from the Arabic sector in three different elementary schools in Israel, in grades 4 to 6 participated. The survey, based on the math reasoning tasks by Healy and Hoyles (1998), is comprised of Algebra and Geometry reasoning tasks. Additionally, 12 of these pupils' teachers were interviewed in order to explore their attitudes toward mathematical reasoning and math proving tasks. Findings show that: 1) There is a difference in students' preferences towards types of reasoning, between grades 4 and 6;2) Sixth graders will be less likely to accept tautologic and inductive reasoning than fourth graders; 3) Elementary school pupils tend to prefer empirical arguments (such as inductive and example-based) as their approach in contrast to the arguments that they believe will receive the highest scores from their teachers. However, findings do not support the hypothesis that there will be a difference in teachers' preferences towards different types of thinking. The research findings and their practical implications are discussed.
\end{abstract}

\section{Keywords}

Pre Deductive, Inductive Numeric Examples, Verbal Generalizations, Generic, Everyday Reasoning, Tautological Reason

\section{Introduction}

While studying mathematics at school, pupils are often required to formulate and test assumptions, to explain and justify conclusions and to prove general theorem or claims. The proof is the mathematical tool through which, by argumentation, the correctness of a mathematical claim is established and given universal vali- 
dation, or the opposite confirming that the claim is false thus refuting it (Hanna, 1989). An argumentation consists of a claim, a statement that the addresser asks the recipient to accept as a truth or a modus operandi, and a conclusion requiring proof (Toulmin, 1969). The methodology of math and science relies on the discursive nature of claims and include their expression and justification, observation of contrary indications, and the social negotiation of data and theories (Sadler \& Fowler, 2006). A high level of argument expresses a high level of literacy (Glassner \& Schwartz, 2001), as elementary school students already apply external justification methods, empiric and analytic justification techniques (Flores, 2002).

Accordingly, one of elementary school's curricular goals is to foster critical thinking skills in students. Critical thinking refers to balanced reflective thinking intended to decide what to believe and how to operate, thus development of critical thinking skills is significant in consuming, processing and implementing new information. Argumentation skills are part of the critical thinking skills set and constitute preliminary and essential background for the decision-making process. Students in elementary grades can potentially develop mathematical claims to be considered as proofs (Stylianides, 2007b). In fact, it is argued that each time they are asked to reason, explain or validate claims, we are fostering these abilities. Unfortunately, many times, students' replies to these questions are poor due to various reasons, some of which originate from verbal and lingual development processes while others stem from age dependent cognitive and intellectual development processes.

The importance of this study is in examining the inductive tendency of elementary school pupils in the Arab sector in Israel, in an effort to explore the developmental process of argumentation and reasoning in grades 4-6. This research differs from prior works in its focus on elementary school pupils as well as the focus on students in the Israeli Arab sector exclusively.

\section{Literature Background}

The status of math teaching in schools today is similar to that of Latin in the 19th century. This profession is considered one of the hardest and most despised for some students. However, mathematic skills are important for all learners in scientific areas, since it is one of the basic tools used in these fields and requirement for higher learning. Moreover, realistic mathematical education and literacy have been shown to have a critical impact on children's likelihood to succeed in their studies later on in life (Papadakis, Kalogiannakis, \& Zaranis, 2016; Zaranis, Kalogiannakis, \& Papadakis, 2013). Like musical notes, the modern mathematical markings have a precise and rigid syntax, most of which were invented only in the 16th century. Thus, beginners might find mathematical language difficult to understand, as words such as "or" have an accurate, and sometimes different, meaning from the everyday use.

Various approaches refer to the development of early childhood thinking and their implications for mathematical education, as most differ in two main aspects. One is the extent to which the structures and developmental processes are domain-dependent, occurring at a uniform or varying in different areas. The other 
pertain to the autonomy of the development process and whether it is innate or environment dependent (Dehaene \& Cohen, 1995). Piaget (1965) argues that children are not passive to the environment but on the contrary, they examine the environment, actively seeking for solutions and asking questions.

Piaget focused on the cognitive processes of collecting and processing knowledge. He compared the development of intelligence to physiological development, while observing four major stages. At each stage, children acquire new intellectual skills based on the previous stages. Although the stage sequence is fixed, each individual has their own pace in light of interpersonal and intercultural differences. Piaget argued that our ability to think develops with age resulting from interaction with the environment, which constantly triggers stimuli in the child leading to learning. Therefore, in order for the child to acquire mathematical concepts such as "proof," he must first understand what it is to prove, or know how to correctly explain things based on this concept. This constructivist approach states that as long as these skills had not been acquired, the child cannot reach the appropriate stage in the development of thinking (Figure 1).

This study focuses on the third and fourth stages in Piaget's model, and the development of the proof concept at these stages from pupils' initial inductive tendency. The stage of concrete operations takes place during elementary school, at the age of 7 - 12. Commonly known, at this age thinking is no longer intuitive or egocentric, as it was during the preschool period, and is characterized by logical thinking, allowing for reasoning and judgment through logic. Some pupils have the ability to understand symbolic or verbal examples while others are able to perform logical actions only in situations involving concrete, tangible objects. Such students still need illustrations through examples. The fourth stage is the most advanced stage in which intellectual development reaches a peak characterized by deductive thinking. A person at this stage can acquire knowledge and use it in the most efficient manner. According to Piaget, the child is gradually released from the grasp of concrete thinking and acquires the ability of abstract thought.

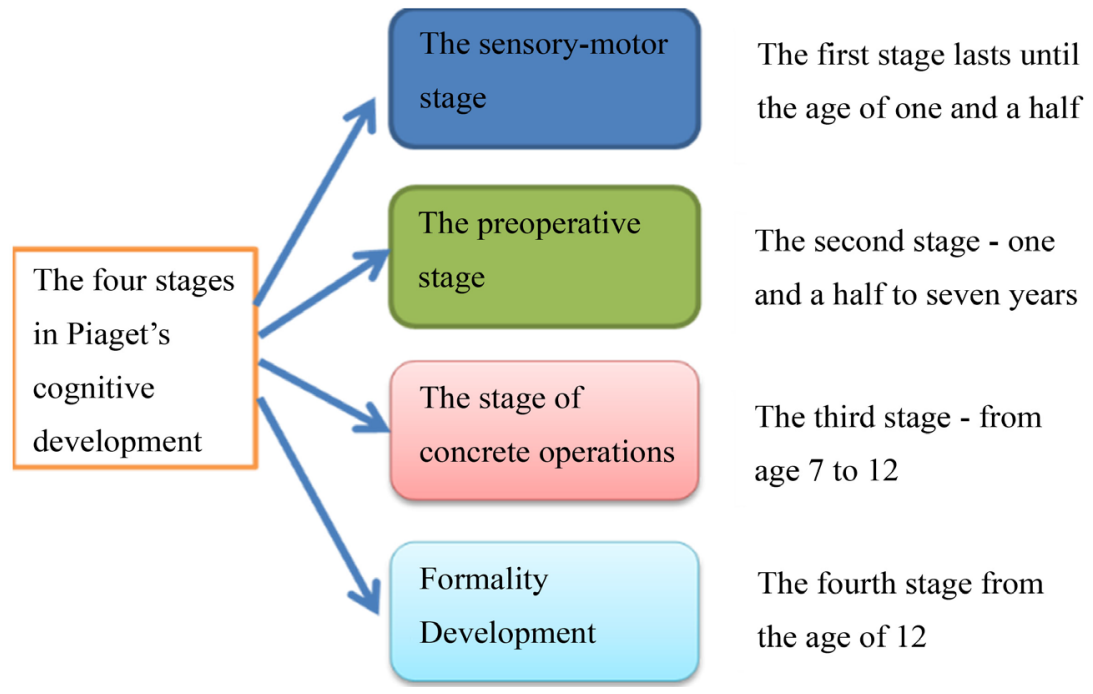

Figure 1. The four stages in Piaget's cognitive development theory (Piaget, 1965). 
Transition from a thinking style is based on the ability to think beyond the tangible, however, even pupils who have acquired formal thinking. However, they need concrete or inductive examples to illustrate the situation of a given argument, or before tackling the task they will have to make inductive inferences. I suggest here that there is a transition stage between the third and fourth stages, or there is room for dividing the two stages (third and fourth) into two parts: third stage, first part, simple concrete operations, and second, complex concrete operations. The fourth is divided into a pre deductive first part, and a second deductive part. In other words, I suggest an intermediate stage; a pre deductive stage that connects the concrete and the formal thinking stages (Figure 2).

Cultivating thinking is a primary goal in all educational institutions and curricula, demanding every teacher's awareness to promoting the learner's thinking. But this is not a sufficient condition in itself (Zohar, 1996). Swartz (2008) offers the concept of stimulating learning in the context of high-order thinking, based on the constructivist approach of developing a deep understanding of a meaningful subject for the learner. This understanding is achieved through problem solving, during which an emphasis is placed on building the learner's knowledge in a thinking community and developing a self-directed and metacognitive and reflective learner. Meta-cognitive intuitive thinking that develops in the early school years is very basic, and only becomes complex and linked to learning processes when learning incorporates explicit use of its components. Metacognitive skills first develop in separate content domains, and only in explicit conceptualization and inclusion processes may transfer beyond domains (Salomon \& Perkins, 1989).

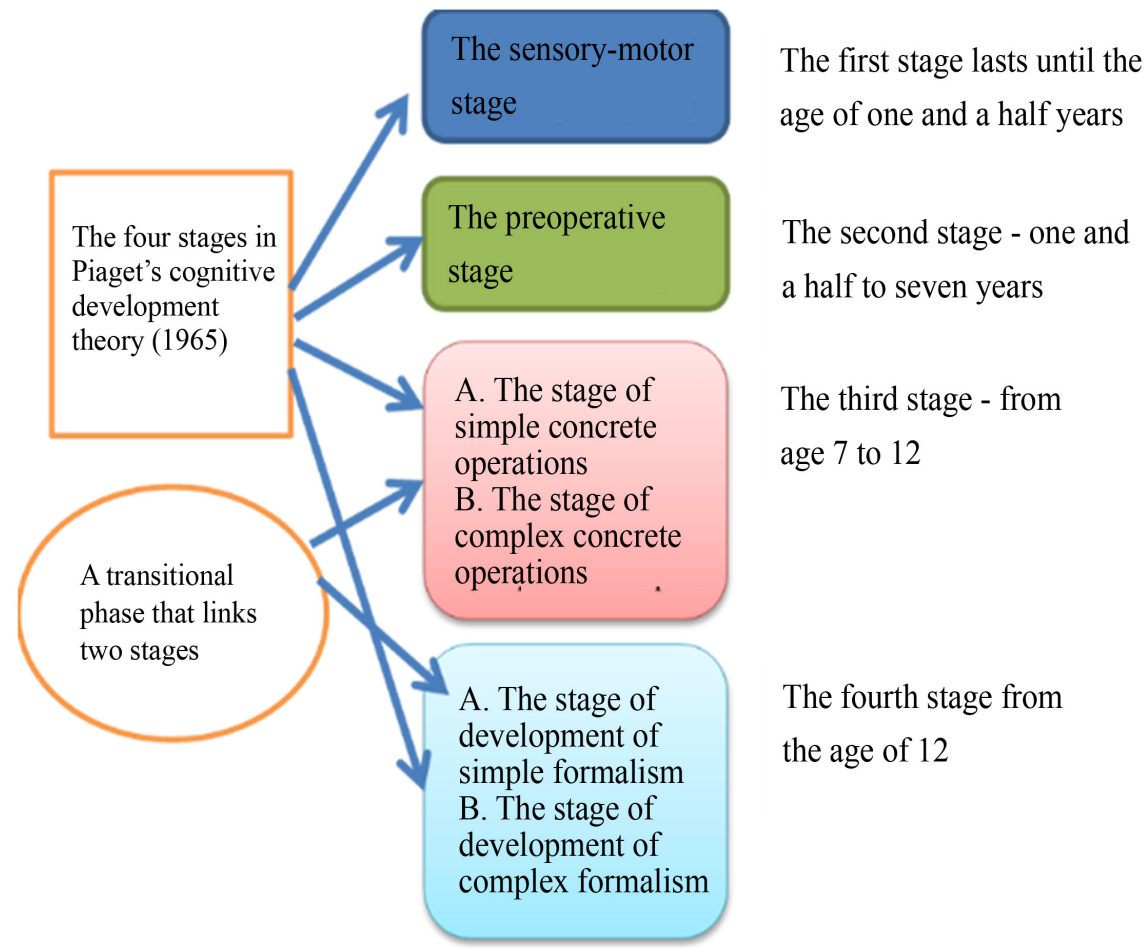

Figure 2. Proposed subdivision in Piaget's cognitive development theory (Piaget, 1965). 
Most researchers have emphasized the need for developing argumentation and discussion skills among students. Means \& Voss (1996) proposed it as a basis for informal reasoning learning, while Duschl (2008) proposed it as a separate subject to be taught in schools. However, in factual life, even teachers who combine argumentative skills in the classroom material promotion rarely do so (Newton, Driver, \& Osborn, 1999).

For the purposes of this study proof is seen as a process of: 1) determining truthfulness of mathematical statements and arguments and validating or refuting them through the construction of mathematical meanings that have individuality and social aspects, the same as Harel \& Sowder (1998) who combine examination and persuasion; and 2) the transfer of these meanings through arguments as described by Stylianides (2007a), by means of groups of conventional statements, modes of argument, and methods of representing a common argument in a society or group or class; that is proof is the product of the process of justification and validation accepted by the specific community. Martin \& Harel (1989) and others indicated the difficulty of teachers' understanding the proof essence and nature, showing they tend to accept inductive claims as proofs, as well as not rejecting deductive but false "proofs" in elementary and high school (Ball, Lubienski, \& Mewborn, 2001; Martin \& Harel, 1989; Goetting, 1995; Knuth, 2002).

Many researchers have pointed to the students' difficulty in tracking and constructing mathematical proofs (Healy \& Hoyles, 2000; Fischbein, 1982; Stylianides \& Stylianides, 2009), the students face difficulties in understanding mathematical evidence, and do not distinguish between inductive-empirical evidence and formal evidence. Studies have found that there is an inductive tendency among students of different ages affected by everyday life; Anderson (1985) calls everyday proofs as "inductive valid arguments" and explains that people create and examine assumptions based on their likelihood, and refute and criticize these assumptions according to subjective experience. Inductive stages are the first in a series of hierarchical stages in the development of the understanding of formal proof (Van Dormolen, 1977). First, the student uses an example to obtain a sense of a given argument; afterwards, he tries several other examples, and examines the common characteristics of all the examples of the claim; finally, the student attempts to obtain formal proof. We can see that the first two stages are inductive and the third is deductive. Following this model, the purpose of this study is to examine the development of acquiring the concept of proof and critical thinking among elementary school students.

\section{Methodology}

\subsection{Sample}

This research is comprised of three studies, held in three Arabic sector elementary schools in Israel. In Study 1, a quantitate study, 267 pupils in grades 4 to 6 participated in a survey. Study 2 is a qualitative study which included 12 teachers of the pupils in study 1. Further statistical analysis of the data collected in 
study 1 are performed in Study 3, in order to test the validity of the evolution of thinking scheme proposed earlier. All three schools are in the same socio-economic measure. All pupils who participated in this research come from heterogenic groups of all levels.

\subsection{Study 1}

\section{Research procedure}

In this research I focus on the way pupils refer to two types of claims: 1) Arithmetic claims: "the sum of each two even numbers is even" and "the sum of each two odd numbers is odd"; and 2) Geometric claims: "the sum of interior angles of each triangle is 180 degrees" and "the sum of each quadrate is 360 degrees". For this purpose, pupils were asked to respond to math reasoning tasks presenting different kinds of reasoning, according to the math reasoning tasks by Healy and Hoyles (1998) which include correct and false reasoning of the two claims mentioned above. Each pupil completed two tasks: one in algebra and another in geometry and were asked in each task to determine according to their opinion, concerning each presented argumentation whether it is correct or not. All the reasoning and argumentation is either explained by inductive numeric examples, verbal generalizations, generic everyday reasoning or tautological reason.

\subsection{Research Tools}

The research tool is a closed math reasoning task in Algebra and in Geometry. It was found that the reliability level (Alpha Cronbach) of all items and all variables is higher than 0.9. The task detailing according to reasoning kind is as in Table 1.

\subsection{Study 2: Teachers Interviews}

After pupils completed the tasks in study 1 , their teachers were interviewed in a semi-structured interview about the same algebraic and geometric claims. The interview was designated to add teachers attitudes regarding students' reasoning preferences. Teachers' textual content was processed and key ideas and motifs were extracted and formed into central themes in the qualitative analysis. We anticipated that in light of the developmental process of mathematical thinking over the years,

Table 1. Types of reasoning in math reasoning task.

\begin{tabular}{cc}
\hline Reasoning of & Reasoning kind \\
\hline Yusif & Inductive \\
Faten & Verbal \\
Shirin & Single example \\
Mariam & Tautological \\
A'beer & Generic
\end{tabular}


there will be a difference between the preferences of adults and the types of reasoning for mathematical arguments, with an emphasis on math teachers. However, insofar as to explaining mathematical argumentation in class, teachers would consider students' need for concretization and examples in accordance with the mathematical thinking development process.

\subsection{Study 3: Further Analysis of Open-Ended Questions}

In this study, teachers in each classroom first explained to students, two claims. One was a claim in algebra and the other was a claim in geometry. Following this, students were asked to explain why the argument was correct while reasoning their answer. Students' answers were coded in two scales. The first coding was of type of reason, either it was tautological, single example, inductive, verbal, generic or visual. The second scale was designed to give a quantitve measure of the quality of the students' answer by a single mark, being a sum of three different marks given as in Table 2

For example, an answer that contained partial reasoning that is tautological and can be applied only to a single case would get an overall mark of $2+1+1=4$. Students' replies were coded and analyzed using one-way Anova, exploring a possible statistical difference in the marks between different grades. The Chi-square test was conducted to look for a statistical difference in the type of reasoning between the three grades.

\subsection{Research Hypotheses}

1) There will be a difference in the students' preferences towards the types of thinking, between grades 4,5 and 6 .

2) Sixth graders will be less likely to accept tautologic and more inductive thinking than fifth and fourth graders.

Table 2. Coding of reasoning types for Study 3.

\begin{tabular}{|c|c|c|}
\hline No. & Reasoning & Mark \\
\hline \multirow{4}{*}{1} & No reasoning & 0 \\
\hline & Contains reasoning but wrong & 1 \\
\hline & Partial reasoning & 2 \\
\hline & Correct reasoning & 3 \\
\hline \multirow{3}{*}{2} & Reasoning which can be generalized & 3 \\
\hline & Reasoning which applies to several examples but cannot be generalized & 2 \\
\hline & Reasoning which only applies to a single example & 1 \\
\hline \multirow{5}{*}{3} & Type of reasoning & \\
\hline & Generic or verbal & 4 \\
\hline & Inductive & 3 \\
\hline & Single example or visual & 2 \\
\hline & Tautological & 1 \\
\hline
\end{tabular}


3) Elementary school students tend to prefer empirical arguments (such as inductive and example) as their approach rather than the arguments that they believe will be the highest scores.

4) There will be a difference in teachers' preferences towards different types of thinking.

5) Primary teachers will disapprove of empirical arguments (e.g., inductive and example), and will not give these reasons the highest scores.

\section{Results}

\subsection{Descriptive Statistics}

The survey was administrated to 244 pupils in algebra and to 267 pupils in geometry. In algebra the sample included 119 boys and 125 girls; there were 83 pupils in the $4^{\text {th }}$ grade, 81 in the $5^{\text {th }}$ grade and 80 pupils in the $6^{\text {th }}$ grade; 82 pupils in the school Alzahra, 80 pupils in the school Alsalam; 82 pupils in the school Ailut-A. In geometry the sample included 126 boys and 141 girls; there were 91 pupils in the $4^{\text {th }}$ grade, 89 in the $5^{\text {th }}$ grade and 87 pupils in the $6^{\text {th }}$ grade. 89 pupils in the school Alzahra, 92 pupils in the school Alsalam; 86 pupils in the school Ailut-A.

\subsection{Research Hypotheses Testing}

Testing the hypothesis that there will be a difference in the preferences of pupils toward types of reasoning, between the $4^{\text {th }}$, the $5^{\text {th }}$ and the $6^{\text {th }}$ grade, a chi-square test was conducted. Supporting the hypothesis, the distribution of reasons was significantly different between the grades in Algebra: $\chi^{2}(8)=33.874, p<0.001$ but not in Geometry $\left(\chi^{2}(8)=10.277, p=0.246\right)$. Regarding pupils' knowledge about their teachers' preferences, this time a chi-square test was not significantly different between the grades in Algebra: $\chi^{2}(8)=12.377, p=0.135$, as more than $50 \%$ of all pupils chose inductive reasoning, but was significant in Geometry $\left(\chi^{2}(8)=24.662, p=0.002<0.01\right)$.

A difference in domain was indicated as significant differences were found between $4^{\text {th }}$ and $6^{\text {th }}$ grade in Algebra: $\chi^{2}(2)=29.932, p<0.001$ but not in Geometry: $\chi^{2}(2)=3.932, p=0.08$, as well as for $5^{\text {th }}$ and $6^{\text {th }}$ grade, (Algebra: $\chi^{2}(2)=$ 24.537, $p<0.001$; Geometry: $\chi^{2}(2)=2.957, p=0.228$ ).

Supporting the hypothesis that there would be a difference in the answers of pupils to questions A1.1 - A1.3, a Friedman test showed that the distribution of reasons was significantly different between the questions for Algebra: $\chi^{2}(2)=$ 35.421, $p<0.001$ as well as for Geometry: $\chi^{2}(2)=24.632, p<0.001$. The hypothesis that there would be a difference in the preferences of pupils toward visual type of reasoning, between the grades, was not supported by a chi-square test.

\section{Analysis of the Answers to the Open Question}

Most of the explanations given by pupils as answers to the open question in geometry, combine visual examples with rectangles or squares which can be attributed to students' intuition. However, sixth graders' answers frequently com- 
bined different representations indicating more developed thinking. Similarly, most of the explanations given by pupils in algebra used a single example or an inductive way of reasoning.

\subsection{A Thematic Analysis of Teachers' Attitudes Regarding Proofs}

A textual qualitative analysis produced five main themes as follows. Depth and complexity-The expressions "depth" and "complexity" versus "simplicity" were used frequently by the teachers. These terms were used for characterizing students' arguments as well as for characterizing questions that require proof as "deep" or "complex" questions. Use of examples-The teachers relate to the students' use of examples as proof, and the development of these examples with age. The examples are not only used by students to prove claims, but also by the teachers while teaching new material or explaining a problem. The texts show that examples play an important role in both processes. The teachers' preference for certain arguments versus what they think about their students' preference-Teachers often distinguish between arguments or examples they would prefer, and those they thought the students would preferable. Teachers preferred to accept formal arguments based on definitions or arithmetic operations, in contrast to everyday life or numerical examples that pupils would prefer. Instrumental value of learning to prove-All the interviews indicated that teachers refer to the learning and teaching of mathematical reasoning as an activity that develops thinking, creativity, and inter-disciplinary thought. Teachers perceive these tasks as requiring the application of high-level thinking. Elementary school does not teach enough mathematical proof-Teachers mentioned lack of teaching time and other curricular constraints as reasons for not investing enough in teaching to prove.

\subsection{Analysis of the Answers to the Open Question}

The Chi-square test was conducted to compare whether there is a statistical difference between grades, finding one in algebra: $\chi^{2}(10)=20.308, p=0.02$ as well as in geometry: $\chi^{2}(10)=40.474, p<0.001$, as sixth grade student use less tautological and visual ways of thinking and use more inductive and verbal ways of thinking. The explanation of student and the way of thinking were coded to additional mark that reflected the way of thinking and correctness. One-way ANOVA test found a difference between grades only in geometry: $\mathrm{F}(2)=33.985$, $p<0.001$, suggesting that the differences between ways of thinking are more significant in geometry than in algebra.

\subsection{Validation}

To validate pupil's own statement by types of reasoning and score they received, two criterions were used-student's total average score and student's math's score. To explore for differences in students' total average score and math score depending on students' preferences toward types of reasoning and between the grades, two-ways ANOVA tests were conducted. The first ANOVA test examined if there 
is a difference in the student's total average scores between types of reasoning, and between the grades, and revealed a significant difference in student's total average score between types of reasoning and between the grades: $\mathrm{F}(14,120)=$ 6.504, $p<0.001$. A main effect for types of reasoning variable was found: $\mathrm{F}(4$, $120)=14.233, p<0.001$. The post hoc tests revealed that there are significant differences between tautological type of reasoning and between every other type of reasoning $(p<0.001)$ for all cases. The second ANOVA test examined a possible difference in math grade between types of reasoning, and between the grades. The model indicated a significant difference in math grade between types of reasoning, and between the grades: $\mathrm{F}(14,120)=6.562, p<0.001$. A main effect for types of reasoning was found: $\mathrm{F}(4,120)=17.283, p<0.001$. The post hoc tests revealed that there are significant differences only between tautological type of reasoning and between every other type of reasoning $(p<0.001)$ for all cases.

To check for a statistical correlation between the score students received in accordance with types of reasoning in pupil's own statement and between student's average score and math score, Pearson correlations were calculated for each grade. The test indicated powerful correlations between the scores according to types of reasoning and between students' total average score and math score for each grade, with some differences between the grades.

\section{Discussion}

\subsection{General}

A survey in which 267 pupils in three different schools in the Arabic sector in Israel participated, has been held in order to learn about the preferences of elementary school pupils toward types of reasoning, in geometry and algebra reasoning tasks. Results of the survey, alongside text analysis of teachers' positions regarding them, reveal a lot on mathematical thinking development.

\subsection{Theoretical Implications of the Results}

The sum total of findings emerging from the empirical chapter of this study indicate differences in the form of reasoning preferred by elementary school pupils as they advance through grades. The resulting picture suggests that as they mature, pupils tend to prefer verbal and generic reasoning over tautological and empirical ones. These findings are consistent and robust beyond different schools and teachers. The basis for a theory that can explain this finding lies in Dewey's (1933) definition of the concept of reflective thinking. This concept attempts to explain the process of creating new information while processing existing information as defined similarly by Bartlett (1932) as well as Lewis \& Smith (1993). Furthermore, it can be suggested that there is a cycle-like process in which reflective thinking produces new information while the pupil progresses into a higher level of thinking. At the new level, reflective thinking is even more complex, allowing for the creation of new information based on what had been learned earlier and so forth. 
At the same time, this process of mathematical argumentation itself constitutes a framework of reflective thinking, in which the student is required to apply formal knowledge in order to create a logical structure that will confirm or refute a claim. In doing so, the pupil creates new information, referring both to the correctness or refutability of the specific claim and to the use of critical logic and thinking tools in mathematical arguments. As the process continues the pupil will be able to apply these methods and information in other fields of knowledge as well, constituting a stage of reflective thinking by definition (Brown, 1987; Flavel, 1979).

Another theoretical contribution that can be attributed to the current research is the confirmation of Eshet's (2004) claim that high-order thinking can be taught and developed at school. Referring to the Passig's (2001) definition in revision of Bloom's taxonomy (1956), one of the high levels of thinking is that of transcription thinking. This level resembles synthesis, as the learner makes use of formal information that already exists, and the techniques he masters, to produce new information. For pupils, this is the process by which they need to prove or refute a mathematical claim. As the findings of the present study suggest, this ability develops with age.

Finally, a unified conceptual framework of the contribution of the present work to theoretical research in this field can be found in the scheme proposed earlier. This scheme seeks to describe how student's learning experiences and other individual traits influence the development of the set of skills whose joint action produces the result of formal thinking in a funnel-like configuration. This structure, based on recurring rounds of feedback and relies on them for improvement, does not necessarily operate linearly and unidirectionally. A substantial part of the theoretical background described and explained various factors and contributors of math inconsistency in students. These factors include teaching methods, inherent difficulties in math, language and visual aspects, perception of mathematics as a set of local rules and more. Producing inconsistencies, these factors disrupt the assimilation of mathematical concepts and procedures. Moreover, this inconsistency adversely affects the development of mathematical intuition, damaging essential elements within the funnel. The respective result may be expressed as pupils might show signs of regression in the level and quality of formal thinking. This can also result in the pupil being treated by inappropriate means, resulting in all-around frustration and even decline in academic achievements. Hence, the importance of teaching lies in its ability to reduce sources of inconsistency, to create positive learning experiences, to empower fundamental skills of math literacy and intuition.

\subsection{Limitations of the Study}

Several limitations may apply to this study, as it was conducted Arab sector schools exclusively, thus potentially limiting the ability to generalize its conclusions. However, it should be noted that the study involved students from three different 
schools and different layers of society. Second, the test used in this study is presented in a format that is unfamiliar to the pupils. Nevertheless, it is possible that if the test was presented in a format that is too familiar, there might have been a ceiling effect. It should also be noted that the test chosen for this study is based on the valid and reliable Math Reasoning Tasks by Healy \& Hoyles (1998). Furthermore, results of study 3 support the findings obtained using the Healy \& Hoyles (1998) reasoning task in study 1 , as they are based on pupils' overall achievements, contribute to the robustness of the findings.

\subsection{Conclusion}

At the basis of this research stands the assumption that development of critical thinking skills is a necessary condition for learning and processing of new information as well as implementing it. In the process of critical thinking argumentation skills are a preliminary and essential component. As shown in the schema describing the development of formal thinking in mathematics and in general, there is a process of recurring feedbacks corresponding with the student's psycho-intellectual development stages. This scheme was validated through an exhaustive examination using quantitative and qualitative techniques. Its explanatory ability for the phenomenon described is very high, in keeping with the research literature that preceded it and offering solutions to material problems arising from previous writing. The findings of the present study indicate that the process is not as linear and unidirectional as Piaget's theory might suggest. Therefore, the descriptive framework proposed in this study may help to somewhat alleviate the contradiction some teachers may experience in the classroom.

\section{Conflicts of Interest}

The author declares no conflicts of interest regarding the publication of this paper.

\section{References}

Anderson, J. A. (1985). Cognitive Psychology and Its Implications. New York: W.H Freeman.

Ball, D. L., Lubienski, S., \& Mewborn, D. (2001). Research on Teaching Mathematics: The Unsolved Problem of Teachers' Mathematical Knowledge. In V. Richardson (Ed.), Handbook of Research on Teaching (pp. 433-456). New York: Macmillan.

Bartlett, F. A. (1932). A Study in Experimental and Social Psychology. New York: Cambridge University Press.

Bloom, B. S. (1956). Taxonomy of Educational Objectives: The Classification of Educational Goals, Handbook I, Cognitive Domain. New York: Longmans, Green.

Brown, A. (1987). Metacognition, Executive, Control, Self-Regulation and Other More Mysterious Mechanisms. In F. E. Weinet, \& R. H. Kluer (Eds.), Metacognition. Motivation and Understanding (pp. 65-116). Hillsdale, NJ: Lawrence Erlbaum.

Dehaene, S., \& Cohen, L. (1995). Toward an Anatomical and Functional Model of Number Processing. Mathematical Cognition, 1, 83-120.

Dewey, J. (1933). How We Think a Restatement of the Relation of Reflective Thinking to the Educative Process. Boston, MA: D.C. Heath \& Co Publishers. 
Duschl, R. (2008). Science Education in Three-Part Harmony: Balancing Conceptual, Epistemic, and Social. Review of Research in Education, 32, 268-291. https://doi.org/10.3102/0091732X07309371

Eshet, Y. (2004). Digital literacy: A Conceptual Framework for Survival Skills in The Digital Era. Journal of Educational Multimedia and Hypermedia, 13, 93-106.

Fischbein, E. (1982). Intuition and Proof. For the Learning of Mathematics, 3, 9-18+24.

Flavel, J. H. (1979). Metacognition and Cognitive Monitoring-A New Era of Cognitive-Developmental Inquiry. American Psychologist, 34, 906-911. https://doi.org/10.1037/0003-066X.34.10.906

Flores, A. (2002). How Do Children Know That What They Learn in Mathematics Is True? Teaching Children Mathematics, 8, 269-274.

Glassner, A. \& Schwartz, B. (2001). From Reading Comprehension to Understanding: From Textual Activities to Literacy Activities in Various Contexts. Script, 2, 11-43.

Goetting, M. M. (1995). The College Students Understanding of Mathematical Proof. Doctoral Dissertation, College Park, MD: University of Maryland.

Hanna, G. (1989). Proofs That Prove and Proofs That Explain. In G. Vergnaud, J. Rogalski, \& M. Artigue (Eds.), Proceedings of the International Group for the Psychology of Mathematics Education Vol. II (pp. 45-51). Paris: PME Books.

Harel, G., \& Sowder, L. (1998). Students' Proof Schemes: Results from Exploratory Studies. In A. H. Schoenfeld, J. Kaput, \& E. Dubinsky (Eds.), Research in Collegiate Mathematics Education III (Vol. 7, pp. 234-283). Providence, RI: AMS, CBMS: Issues in Mathematics Education.

Healy, L., \& Hoyles, C. (1998). Justifying and Proving in School Mathematics: Technical Report on the Nationwide Survey. London: Institute of Education, University of London.

Healy, L., \& Hoyles, C. (2000). A Study of Proof Conceptions in Algebra. Journal for Research in Mathematics Education, 31, 396-428. https://doi.org/10.2307/749651

Knuth, J. (2002). Secondary School Mathematics Teachers' Conceptions of Proof. Journal for Research in Mathematics Education, 33, 379-405.

https://doi.org/10.2307/4149959

Lewis, A., \& Smith, D. (1993). Defining Higher Order Thinking. Theory into Practice, 32, 131-137. https://doi.org/10.1080/00405849309543588

Martin, W. G., \& Harel, G. (1989). Proof Frames of Preservice Elementary Teachers. Journal for Research in Mathematics Education, 20, 41-51. https://doi.org/10.2307/749097

Means, M. L., \& Voss, J. F. (1996). Who Reasons Well? Two Studies of Informal Reasoning among Children of Different Grade, Ability and Knowledge Levels. Cognition \& Instruction, 14, 139-179. https://doi.org/10.1207/s1532690xci1402_1

Newton, P., Driver, R., \& Osborne, J. (1999). The Place of Argumentation in the Pedagogy of School Science. International Journal of Science Education, 21, 553-576. https://doi.org/10.1080/095006999290570

Papadakis, S., Kalogiannakis, M., \& Zaranis, N. (2016). Improving Mathematics Teaching in Kindergarten with Realistic Mathematical Education. Early Childhood Education Journal, 45, 369-378. https://doi.org/10.1007/s10643-015-0768-4

Passig, D. (2001). A Taxonomy of ICT Mediated Future Thinking Skills. In H. Taylor, \& P. Hogenbirk (Eds.), Information and Communication Technologies in Education: The School of the Future (pp. 103-112). Boston: Kluwer Academic Publishers. https://doi.org/10.1007/978-0-387-35403-3_9 
Piaget, J. (1965). The Child's Conception of Number. New York: W.W. Norton \& Co.

Sadler, T. D., \& Fowler, S. R. (2006). A Threshold Model of Content Knowledge Transfer for Socioscientific Argumentation. Science Education, 90, 986-1004.

https://doi.org/10.1002/sce.20165

Salomon, G., \& Perkins, D. N. (1989). Rocky Roads to Transfer: Rethinking Mechanisms of a Neglected Phenomenon. Educational Psychologist, 24, 113-142.

https://doi.org/10.1207/s15326985ep2402_1

Stylianides, A. J. (2007a). Introducing Young Children to the Role of Assumptions in Proving. Mathematical Thinking and Learning, 9, 361-385. https://doi.org/10.1080/10986060701533805

Stylianides, A. J. (2007b). The Notion of Proof in the Context of Elementary School Mathematics. Educational Studies in Mathematics, 65, 1-20.

https://doi.org/10.1007/s10649-006-9038-0

Stylianides, G. J., \& Stylianides, A. J. (2009). Facilitating the Transition from Empirical Arguments to Proof. Journal for Research in Mathematics Education, 40, 314-352.

Swartz, R. J. (2008). Engineering Learning. Educational leadership, 65, 26-31.

Toulmin, S. E. (1969). The Use of Argument. Cambridge, AT: The University Press.

Van Dormolen, J. (1977). Learning to Understand What Giving a Proof Really Means. Educational Studies in Mathematics, 8, 27-34. https://doi.org/10.1007/BF00302502

Zaranis, N., Kalogiannakis, M., \& Papadakis, S. (2013). Using Mobile Devices for Teaching Realistic Mathematics in Kindergarten Education. Creative Education, 4, 1-10. https://doi.org/10.4236/ce.2013.47A1001

Zohar, A. (1996). Learn, Think and Learn to Think. Jerusalem: Branco Weiss Institute for Cultivation of Thinking. 